International Journal of Automotive and Mechanical Engineering (IJAME)

ISSN: 2229-8649 (Print); ISSN: 2180-1606 (Online);

Volume 13, Issue 3 pp. 3728 - 3741, December 2016

CUniversiti Malaysia Pahang Publishing

DOI: https://doi.org/10.15282/ijame.13.3.2016.15.0305

\title{
Propagation and scattering of guided waves in composite plates with defects
}

\author{
Bibi I. S. Murat ${ }^{*}$ and P. Fromme ${ }^{2}$ \\ ${ }^{1}$ Faculty of Mechanical Engineering, Universiti Teknologi MARA, \\ 40450 Shah Alam, Selangor, Malaysia \\ *Email: intansuraya@salam.uitm.edu.my \\ Phone: +60355435224; Fax: +60355435160 \\ ${ }^{2}$ Department of Mechanical Engineering, University College London, \\ WC1E 7JE London, UK
}

\begin{abstract}
Failure in aerospace composites owing to low-velocity impact raises a significant maintenance concern because it can lead to invisible damage. For the aerospace industry, such defects pose a potential danger to the structural integrity of aircraft. This in turn jeopardises passenger safety and incurs high repair costs. Hence, it is important to efficiently monitor composite structures during the service life. In this study, the potential of low-frequency guided ultrasonic waves for health monitoring in laminated composite plates is investigated. This study focuses on the use of the first antisymmetric guided wave mode $\left(\mathrm{A}_{0}\right)$. The first part of this study is to investigate the propagation of the $\mathrm{A}_{0}$ mode in three different undamaged composite plates experimentally. The dispersive and anisotropic behaviour are in agreement with the results of finite element simulations and semi-analytical analysis. The final part of this study presents the scattering of guided waves at the impact damage using a non-contact laser interferometer. Significant scattering activities were observed and the impact damage size can be estimated to be about $10 \times 25 \mathrm{~mm}$. In conclusion, these results demonstrate the potential of guided ultrasonic waves for the inspection of aerospace composite structures.
\end{abstract}

Keywords: Composite plates, guided ultrasonic waves, non-destructive testing.

\section{INTRODUCTION}

In general, aerospace composites, in the form of carbon fibre laminates, consist of layers of polymer matrix reinforced with high-strength carbon fibres. In a complete investigation by Richardson and Wisheart [1], it is stated that one major concern related to composite laminates is their susceptibility to sustain low-velocity impact damage. The problem with low-velocity impact damage in composites is that it is often not visible or is barely visible in a typical visual inspection [2]. Shyr et al. [3] found that visible damage can be clearly detected and remedial action could be taken immediately to maintain the structural integrity. However, this is often not the case for impact damage in composites. A major concern is the growth of hidden, undetected defects caused by low-velocity impacts and fatigue [4]. Various different failure modes and mixed damage modes may occur [2, 5]. Matrix cracking, delamination, fibre debonding and fibre breakage are examples of various failure modes under low-velocity impact $[6,7]$. Wisnom [8] highlights that failure to detect these internal damages at an early stage may result in a catastrophic failure of the composite structure. In order to maintain the quality and reliability of a composite structure, non-destructive testing (NDT) is commonly used. Visual inspection, ultrasonic 
testing [9], acoustic emission [10], X-ray radiography [11] and eddy-currents [12] are amongst the NDE methods employed in aerospace inspection. However, for the large aircraft structures most methods are very time consuming and costly, and interrupt the aircraft service. This indicates a need for rapid inspection and cost-effective methods for monitoring large composite structures.

One possible method, the guided ultrasonic waves NDE method, has been chosen to be further explored in this study [13]. Using low excitation frequency, guided waves can propagate over long distances with limited energy loss. From a single location, the guided waves can cover large areas, which helps to reduce the inspection time. The reflection of the propagating wave at defects enables rapid detection of defects in large structures [14]. This method has been used successfully for the detection of defects in large metal plates and long pipes, i.e., for corrosion and crack detection [15]. However, the behaviour of the guided waves is somewhat more complicated in composite structures owing to the physical properties of composites that are generally inhomogeneous and anisotropic in nature. The capability of the guided waves for the inspection of aerospace structures is still under investigation. Many factors could affect the wave propagation and scattering [16-18]. The properties of guided waves in anisotropic plates are more complicated than those in isotropic plates [19, 20]. The plate geometry, material properties, fibre arrangement, fibre orientation, transducer frequency, excitation mode and type of impact damage are among the factors. Moreover, multiple reflections can form an infinite number of wave modes through the thickness. Wilcox et al. [21] identified that the modes can be either symmetric, noted as $S_{n}\left(S_{0}, S_{1}, S_{2} \ldots . . S_{n}\right)$, or antisymmetric, noted as $A_{n}\left(A_{0}, A_{1}, A_{2} \ldots . . S_{n}\right)$, and these modes are generally dispersive [22]. Each wave mode has a different speed, a different wavelength and a different wave pattern (mode shape) across the thickness, which can add to the complexity of the received signals [22]. For waves propagating in composite laminates, the wave interaction depends on many factors such, as the excitation frequency, the geometry of the structure, material properties, direction of propagation and interlaminar conditions [23-25]. Although the benefits of using guided waves are huge, these factors describe the difficulties in using guided waves for composite inspection. Hence, knowledge of the properties of guided wave propagation in composites is important for the successful implementation in nondestructive evaluation. Therefore, the objective of this study is to investigate the potential of guided ultrasonic waves for detecting impact damage in composite plates. This study aims to achieve a better understanding of guided wave propagation in composite plates and their interactions with impact damage. The outcomes of this research will help to establish an efficient technique for the inspection of composite materials using guided ultrasonic waves.

\section{METHODS AND MATERIALS}

Two sets of guided wave experiments were performed. The first set of experiments was performed on four undamaged composite plates with different thicknesses and material properties. The second experiment was performed on two defective composite plates for the detection and characterisation of impact damage. Details can be found in Table 1.

The first plate was a large cross-ply carbon fibre plate. The plate was constructed from 24 prepreg plies in alternating $\left[0^{\circ} / 90^{\circ}\right]$ orientations with symmetry at the mid-plane. The material of the prepregs was HEC fibre (60\%)/SE84 HT epoxy (40\%). Each ply has a nominal thickness of $0.15 \mathrm{~mm}$, giving a total plate thickness of $3.6 \mathrm{~mm}$. The second plate was a small unidirectional plate. The plate was constructed from 24 prepreg plies in 
parallel alignment $\left[0^{\circ}\right]$. The material and total thickness were the same as those for the first plate. The final two plates were small cross-ply plates, consisting of eight prepreg layers with a symmetric layup sequence of [0/90]. The plates were manufactured using carbon-fibre Tenax HTS (65\%) pre-impregnated with Cytec 977-2 epoxy resin (35\%). The ply thickness was $0.25 \mathrm{~mm}$ and eight plies were used, giving a plate thickness of 2 $\mathrm{mm}$. The centres of the plates were subjected to a $7.4 \mathrm{~J}$ impact using a hemispherical 15 $\mathrm{mm}$ impactor head, following standard drop weight impact procedures. The size of the impact damage can be estimated to be about $10 \mathrm{~mm}$ in length and $20 \mathrm{~mm}$ in width.

Table 1. Details of the composite specimens.

\begin{tabular}{cccc}
\hline Test plates & Large cross-ply & UD plate & Small cross-ply \\
\hline Materials & HEC Fiber (60\%)/SE84 & HEC Fiber $(60 \%) /$ & Carbon Tenax HTS (65\%)/ \\
& HT epoxy (40\%) & SE84 HT epoxy $(40 \%)$ & Cytect 077-2 epoxy resin \\
No. of plies & & & $(35 \%)$ \\
Orientation of & {$[0 / 90 / 0 / 90 / 0 / 90 / 0 / 90 / 0 / 90 /$} & All plies in $0^{0}$ direction & 8 \\
plies & Symmetry at mid-plane $]$ & & {$[0 / 90 / 0 / 90 /$ Symmetry at } \\
Thickness (mm) & 3.6 & 3.6 & mid-plane $]$ \\
Impact testing $(\mathrm{J})$ & - & - & 2 \\
\hline
\end{tabular}

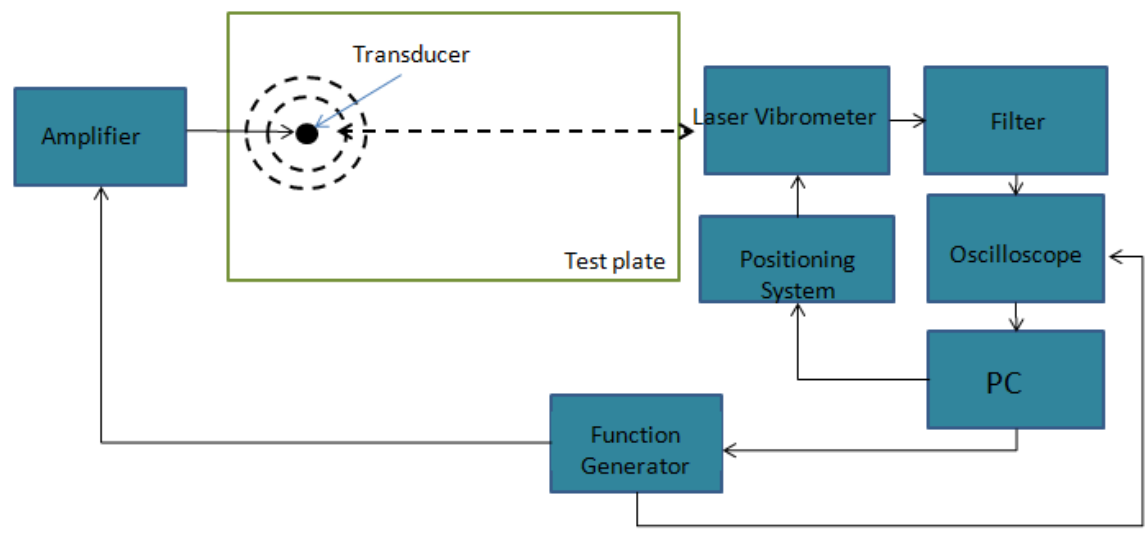

Figure 1. Schematic diagram of the guided ultrasonic wave experimental setup.

Figure 1 shows the setup for the guided wave measurements, which consists of a modular scanning rig controlled via LabView from a computer. The excitation signal is generated by a function generator as a voltage signal, amplified by a wide band amplifier and then applied to a piezoelectric transducer. A laboratory-made piezoelectric transducer, polarised through the thickness, was used to excite the $\mathrm{A}_{0}$ wave mode. The discs act in good approximation as a point source and the waves propagate radially outwards. A brass backing mass was carefully bonded to the piezoelectric disc using epoxy glue. Electrical voltage is applied via a copper wire that was soldered to the backing mass. The piezoelectric transducer was directly bonded onto a thin layer of silver coated paint (Electrolube SCP03B) on the composite plate. The use of silver paint acts as ground connection for the transducer. When the voltage is applied to the piezoelectric transducer, the piezoelectric disc contracts and expands. This generates a vertical force to the plate surface and excites primarily the $\mathrm{A}_{0}$ mode. Good and repeatable signals were obtained. The displacement field in the specimen is measured using a heterodyne laser vibrometer, 


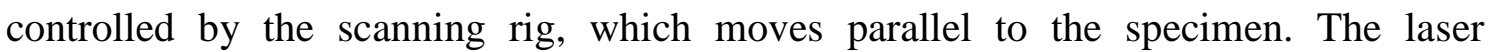

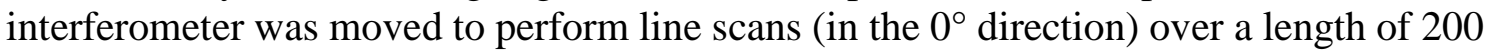

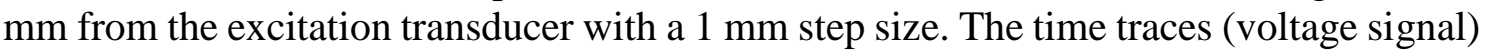

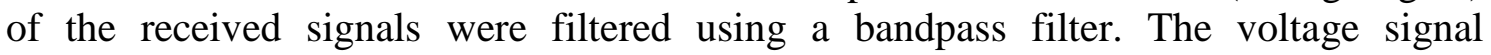

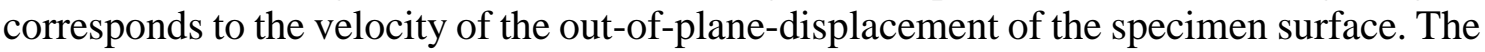

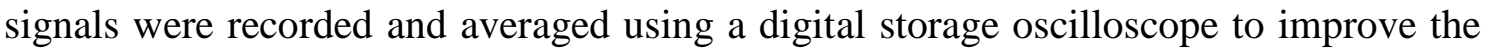

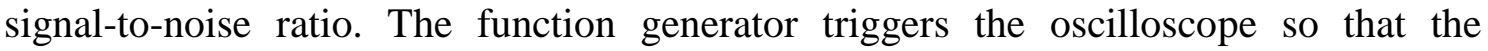

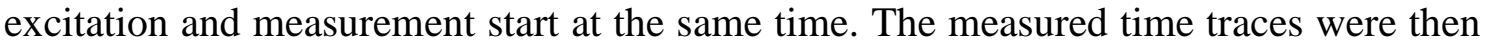

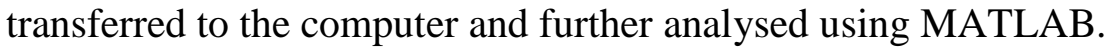

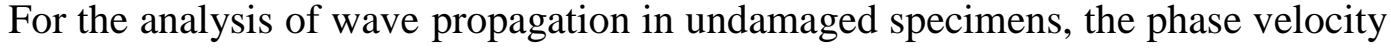

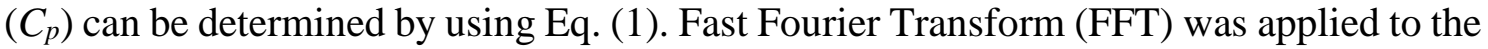

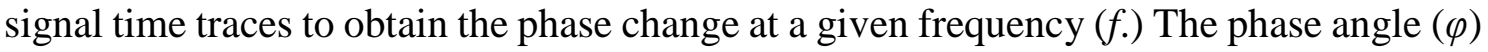

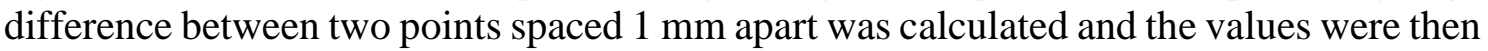

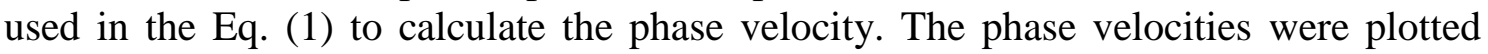

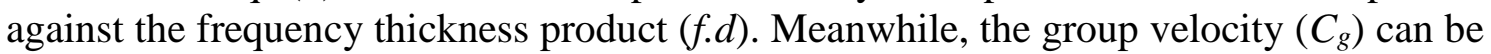

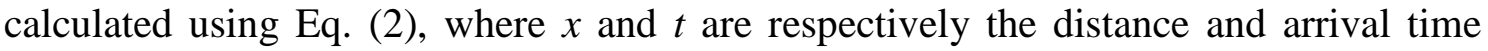

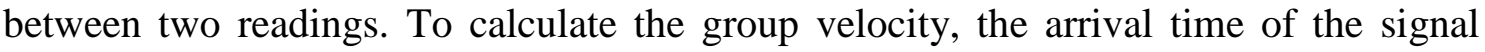

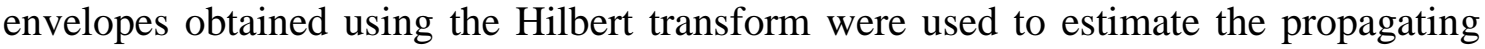

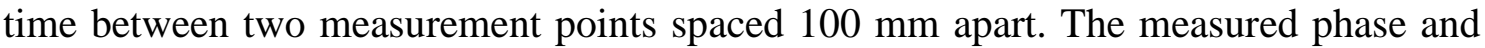

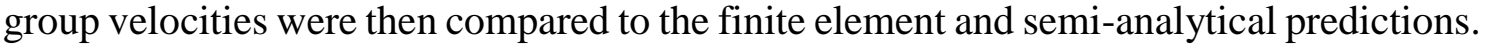

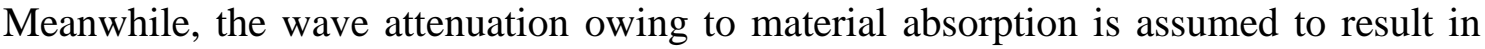

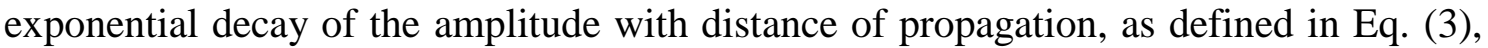
. where $A_{1}, A_{2} r_{1}$ and $r_{2}$ are respectively the amplitudes and radial distances. at to measured locations and $\alpha$ is the attenuation coefficient owing to the material damping.

$$
\begin{array}{r}
C_{p}=2 \pi f\left(\frac{x_{2}-x_{1}}{\varphi_{2}-\varphi_{1}}\right) \\
C_{g}=\frac{x_{2}-x_{1}}{t_{2}-t_{1}} \\
\alpha=\frac{1}{r_{2}-r_{1}} \ln \left(\frac{A_{2} \sqrt{\frac{r_{2}}{r_{1}}}}{A_{1}}\right)
\end{array}
$$

The wave scattering by the impact damage was measured on the small cros-ply plates, where the plates had barely visible impact damage from the impact tes. An area of $40 \times 40 \mathrm{~mm}$ around the impact damage was monitored using a raster scar with step size of $1 \mathrm{~mm}$. The time traces of the received signals were collected and further.processed in MATLA. 8 . The Hilbert transform was applied to the received signas and the amplitudes of the signal envelope were used to plot the wave field. In order to enderstand the behaviour of the propagating wave field in the composite plate with impast damage, a visualisation based on the arrival time of each monitored signal was constructod.

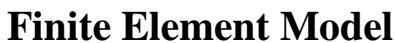

Guided wave propagation problems were modelled using the finite element (FE) method. The commercial software package ABAQUS/Explicit was used to simulate the wave propagation in composite plates. Wave propagation is introduced when the initial equilibrium is disturbed by the application of forces or displacement on nodes. The displacement in elements, which can be obtained by integrating the accelerations twice, is then used to solve the wave propagation problem. The accelerations at the beginning 
of the time step are completely determined by the mass and force acting on the elements. With the explicit method, the state of the elements is advanced through an increment of time using known values from the previous time step. For computational stability, the time increment must be smaller than the critical time step. In wave propagation modelling, the critical time step $\left(\Delta t_{c r}\right)$ can be defined as the transit time at the highest wave speed through the smallest element in the model. Eq. (4) is used to satisfy the stability requirement, where $l_{e}$ and $C_{l}$ are respectively the smallest element length and the fastest wave speed of the material. The length of the element $\left(l_{e}\right)$ is typically calculated from the shortest wavelength $\left(\lambda_{\min }\right)$ to be analysed, as shown in Eq. (5). For the accuracy of the simulation, typically at least 10 elements per shortest wavelength are defined [26]. The chosen time increment must be below the stability limit. These criteria lead to a large computational memory demand.

Similar to the experimental specimens, three types of composite plates were modelled. Figure 2 shows the illustration of the plate model, but all plates were modelled with a large size of $1 \times 1 \mathrm{~m}$ in order to reduce any unwanted edge reflections and to allow simpler analysis of the main guided wave properties. Element size of $1 \mathrm{~mm}$ in the $\mathrm{x}$ - and $\mathrm{y}$ - directions (along the plate) and $0.25 \mathrm{~mm}$ in the z-direction (one element per layer through thickness) was employed, resulting in 8 million elements to model the plate. The element type was chosen as an eight-node linear brick with reduced integration (C3D8R). The employed largest element size $(1 \mathrm{~mm})$ and time step $(0.01 \mu \mathrm{s})$ fulfilled the stability criteria. For the generation of solid homogenous and layered models, the orthotropic homogenised $\left[0^{\circ} / 90^{\circ}\right]$ and the orthotropic unidirectional $\left[0^{\circ}\right]$ properties were assigned. The properties were obtained from research by Neau et al. [27]. Rayleigh damping was set to $B=30 \mathrm{~ns}$ to match the guided wave attenuation measured for the undamaged part of the composite specimens. Out-of-plane excitation was introduced to generate an $\mathrm{A}_{0}$ Lamb wave propagating along the plate. The excitation signal consisted of a five-cycle sinusoidal tone burst modulated by a Hanning window. The pulse was generated with arbitrary low amplitude based on Eq. (6), as used in the experiments. The excitation location was placed $100 \mathrm{~mm}$ from the centre of the delamination to match the experimental setup (200 $\mathrm{mm}$ for the large delamination model). The out-of-plane displacement was monitored at the same locations as for the line and circular scans performed experimentally. A Hilbert transform was used to extract the maximum of the signal envelopes for each monitoring node.

$$
\begin{gathered}
\Delta t \leq \Delta t_{c r}=\frac{l_{e}}{C_{l}} \\
l_{e}=\frac{\lambda_{\min }}{10 \text { elements }} \\
A m p=0.5 *\left(1-\cos \left(\frac{2 \pi f * t}{\text { no.of cycles }}\right)\right) *(\sin (2 \pi f * t)
\end{gathered}
$$

To validate both simulation and experimental results, DISPERSE, a software package developed at Imperial College London by Cawley et al [26], was used to theoretically predict the guided wave propagation characteristics. Two DISPERSE models were used to define the composite plates: homogenised and layered models, similar to those defined in the FE models. Similarly to the FE simulations, each model was defined using lossy orthotropic stiffness properties [27] where both real and imaginary stiffness properties were used as the inputs for the material properties. From Neau et al [27], the uncertainty of the imaginary properties is significantly larger than for 
the real constants. Thus, it is expected that the attenuation measurements are going to have larger errors than the velocity measurements.

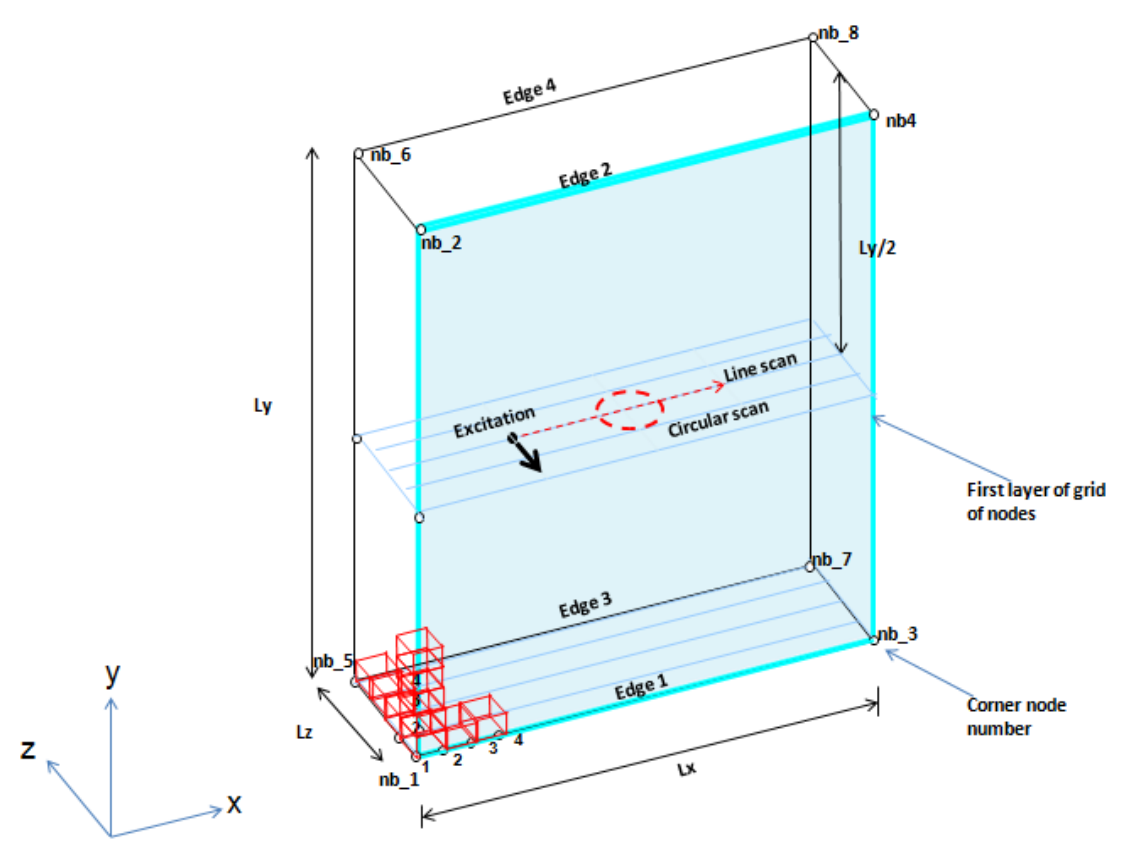

Figure 2. Illustration of the plate geometry; the excitation and monitoring points are placed in the middle of plate for the generation and detection of the $A_{0}$ mode; corner nodes number identified as nb_i $(i=1,2,3 \ldots n)$; edges $1,2,3$ and 4 were set as the boundaries of the plate.

\section{RESULTS AND DISCUSSION}

The propagation of the $\mathrm{A}_{0}$ mode was measured using a non-contact laser interferometer and compared to the results of the Finite Element (FE) simulations as well as to the DISPERSE semi-analytical predictions. The aim of this study is to investigate the wave dispersion and attenuation of the $\mathrm{A}_{0}$ mode in anisotropic plates.

\section{Group and Phase Velocities}

This section reports the velocity dispersion characteristic of the $\mathrm{A}_{0}$ guided wave mode in three types of undamaged composite plates, focused on the measurements in the $0^{\circ}$ direction. Figure 3 shows the comparisons of the measured group and phase velocities together with predictions by DISPERSE and FE analysis. Comparable results can be observed for the DISPERSE and FE predictions (within 1\% error) in calculating the group and phase velocities for three different types of plates. This is as expected because both simulations were using the same stiffness coefficients (real part), which determines the guided wave velocity in plates. Comparing the predicted results to the experimental results, the measured phase velocities are scattered around the predicted values reasonably well. A larger error can be observed at the higher frequency region with the largest (approximately less than 30\% error) obtained from the $2 \mathrm{~mm}$ cross-ply plate. In term of velocity dispersion, it can be seen that the $\mathrm{A}_{0}$ mode is highly dispersive in the frequency range below $50 \mathrm{kHz}$ for all composite plates. This wave dispersion is undesirable in inspection systems because there will be an increase in the pulse width and a decrease in the amplitude with propagation distance owing to the broadening 
distribution of the wave energy [21]. The reduction in amplitude limits the propagation distance, and the increase in signal duration worsens the resolution that can be obtained.
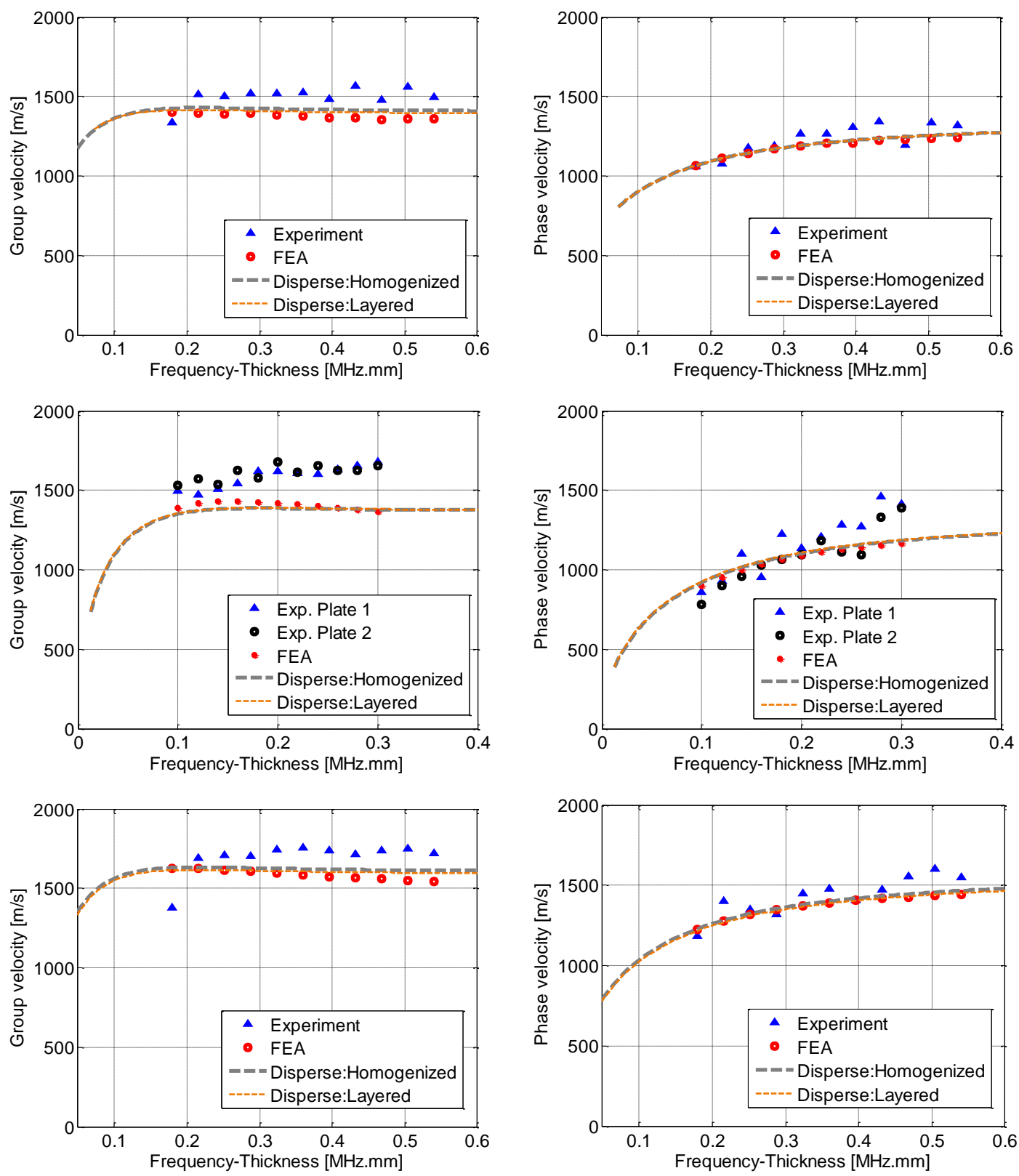

Figure 3. Measured and predicted velocities for the $A_{0}$ mode propagation in the composite plates; a) and (b) for the $3.6 \mathrm{~mm}$ cross-ply plate, (c) and (d) for the $2 \mathrm{~mm}$ cross-ply plate, and (e) and (f) for the $3.6 \mathrm{~mm}$ UD plate; $100 \mathrm{kHz}$; measured in $0^{\circ}$ direction.

On the contrary, Figure 3 also shows that the dispersion of the $\mathrm{A}_{0}$ mode in all plates is smaller above $50 \mathrm{kHz}$. Within the frequency range of the excited wave packet $(50 \mathrm{kHz}$ to $150 \mathrm{kHz})$, there were small dispersions in the group velocities. Wilcox et al. [21] explained that different frequency components in a wave packet travel at different speeds, so the shape of the wave packet is expected to have a small distortion while traveling owing to the differences in the arrival times of each frequency component. This 
means that the wave packet retains its shape as it travels and the differences in the arrival times are very small. This feature is desirable for the SHM of composites because a dispersive wave packet will lead to a complicated signal processing [21]. For the defect characterisation measurements, a $100 \mathrm{kHz}$ frequency was chosen as the nominal excitation frequency as its wave packet is less dispersive.

\section{Attenuation}

Both DISPERSE models of the three types of plates were further analysed to estimate the attenuation coefficient in the frequency range from $50 \mathrm{kHz}$ to $150 \mathrm{kHz}$. From Figure 4, the overall trend of the simulated models is comparable to the experimental results, although it gives slightly higher values. The attenuation increased with frequency for all three types of composite plates, as expected for the $\mathrm{A}_{0}$ mode. A small variation of the measured coefficients at frequencies below $100 \mathrm{kHz}$ can be observed, which could be owing to measurement errors. At frequencies above $100 \mathrm{kHz}$ the values became more stable. For the $3.6 \mathrm{~mm}$ cross-ply plate (Figure 4), the measured attenuation values increased from approximately $0.05 \mathrm{~dB} / \mathrm{mm}$ at $50 \mathrm{kHz}$ to $0.15 \mathrm{~dB} / \mathrm{mm}$ at $150 \mathrm{kHz}$. This gives a rough estimation of an approximately $0.10 \mathrm{~dB} / \mathrm{mm}$ increment over the frequency range. Similarly, the attenuation coefficients for the $3.6 \mathrm{~mm}$ UD plate were measured as $0.001 \mathrm{~dB} / \mathrm{mm}$ at $50 \mathrm{kHz}$ and increased to approximately $0.11 \mathrm{~dB} / \mathrm{mm}$ at $150 \mathrm{kHz}$, lower than for the $3.6 \mathrm{~mm}$ cross-ply plate. Since the results compare reasonably well, these attenuation values hold important information to determine how far the $\mathrm{A}_{0}$ mode can travel at certain excitation frequencies and can be used for future reference. The increase in attenuation with frequency imposes an upper frequency limit on inspections. From these attenuation results, the frequency-dependency of the $\mathrm{A}_{0}$ mode wave attenuation has been shown and validated.

Comparisons between the attenuation coefficients of the three different composite plates show the influence of plate thickness, material properties and fibre arrangement. From Figure 4, it can be seen that the $2 \mathrm{~mm}$ plate has lower wave attenuation at $100 \mathrm{kHz}$ $(\alpha=0.046 \mathrm{~dB} / \mathrm{mm})$ than the $3.6 \mathrm{~mm}$ plate $(\alpha=0.099 \mathrm{~dB} / \mathrm{mm})$. Referring to literature for a qualitative comparison, Herrmann et al. [28, 29] also showed a similar behaviour of the attenuation coefficient for the $A_{0}$ mode in 12-ply and 16-ply UD plates. The attenuation values were respectively $=0.025 \mathrm{~dB} / \mathrm{mm}$ and $0.06 \mathrm{~dB} / \mathrm{mm}$ (in the $0^{\circ}$ direction). Two reasons seem to correlate to this behaviour: (i) the material thickness and (ii) differences in the materials used for their fibre-matrix system. Thicker materials generally show greater damping owing to increased energy absorption. Various studies have shown that the wave absorption coefficient of a composite material is a function of thickness and porosity. Furthermore, Prosser [30] discussed the influence of plate thickness on wave attenuation. It was demonstrated that the thicker plate increased the wave attenuation. To relate to the second reason, Biwa [31] indicated that a major governing factor of wave attenuation is the viscoelastic absorption in the matrix. This results in an increase of the wave attenuation with increasing matrix content. These seem to support the findings presented here, where the $3.6 \mathrm{~mm}$ cross-ply plate has higher matrix content (40\%) than the $2 \mathrm{~mm}$ cross-ply plate (35\%). However, it should be noted that both types of plates were made of different fibre-matrix systems, which could additionally contribute to the different wave attenuation of both plates.

From Figure 4, a comparison between the $3.6 \mathrm{~mm}$ UD and the $3.6 \mathrm{~mm}$ cross-ply plates shows that the fibre arrangement (alternately arranged into the $0^{\circ}$ and $90^{\circ}$ directions) contributed to higher attenuation than the one with all fibres arranged in the $0^{\circ}$ direction. Although both plates are made of the same number of plies and have the 
same material properties, the wave attenuation differed by $13 \%$. This could be owing to the direction of measurements taken along the fibre direction $\left(0^{\circ}\right)$ of the UD plate, in which it has higher stiffness properties than in the cross-ply plate. In comparison to what has been published by other researchers, Ono and Gallego [32] measured attenuation coefficient $(\alpha)$ of the $A_{0}$ mode $=0.08 \mathrm{~dB} / \mathrm{mm}$ in a 16 cross-ply composite plate and $\alpha=$ $0.06 \mathrm{~dB} / \mathrm{mm}$ in a 16-ply UD plate in the $0^{\circ}$ direction. Although the measurements were performed at $300 \mathrm{kHz}$, their results are qualitatively similar to the ones presented here, where the attenuation in the UD plate is lower than the cross-ply plate, although their number of plies and materials were the same.

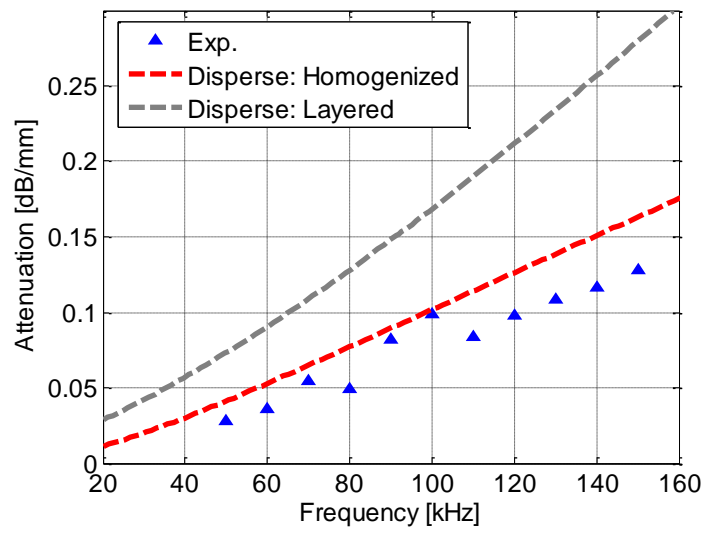

(a)

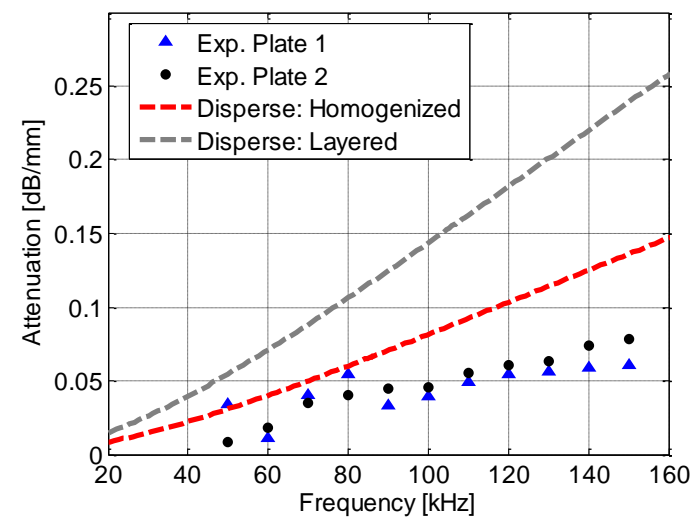

(b)

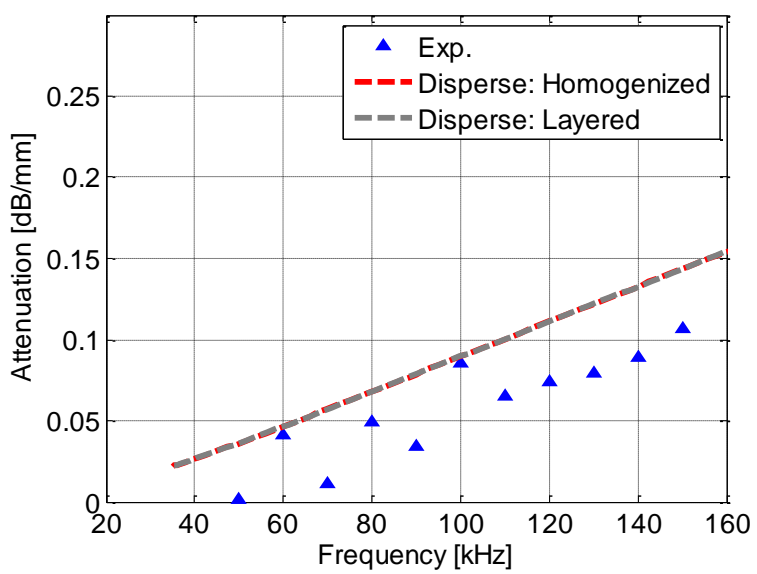

(c)

Figure 4. Measured frequency-dependent attenuation coefficient together with DISPERSE predictions; corrected for geometrical beam spreading; excitation frequency 50-150 kHz; measured in $0^{\circ}$ direction; (a) 24-cross ply; (b) 8-cross ply; (c) 24unidirectional composite plates.

\section{Scattering of Guided Waves at Impact Damage}

Figure 5 presents the guided wave fields at various time snapshots for damaged composite plates 1 and 2. It can be seen that the incident wave interacts with the impact damage and causes scattering within the damaged region. Relatively weak scattering by the damage is present when the incident wave arrives (Figure 5a and Figure 5c), then a significant increase of the scattering is apparent when the wave has travelled past the damaged area (Figure 5b and Figure 5d). Based on the observation, a significant portion of the waves is 
also reflected back from the exit of the impact damage. These reflected waves travel within the damaged region and keep reflecting back at both the entrance and exit of the impact damage. As a consequence of these multiple reflections, a considerable amount of guided wave energy is trapped inside the impact damage area. This causes an increase in the amplitude of the wave in that region. The amplitude of the transmitted waves diminished noticeably after passing through the impacted area. Similar wave behaviour was also observed by Sohn et al. [33], where the measurement was performed on a quasiisotropic composite plate. In the FE results in a different publication [34], a similar reduction in the amplitude past the delamination area was observed, which is in agreement with this experimental measurement. Comparing both specimens, which were treated with the same $7.4 \mathrm{~J}$ impact energy, it can be seen that guided wave scattering in both plates is unique and such variations are expected owing to the complexity in the failure mechanism of impact damage.

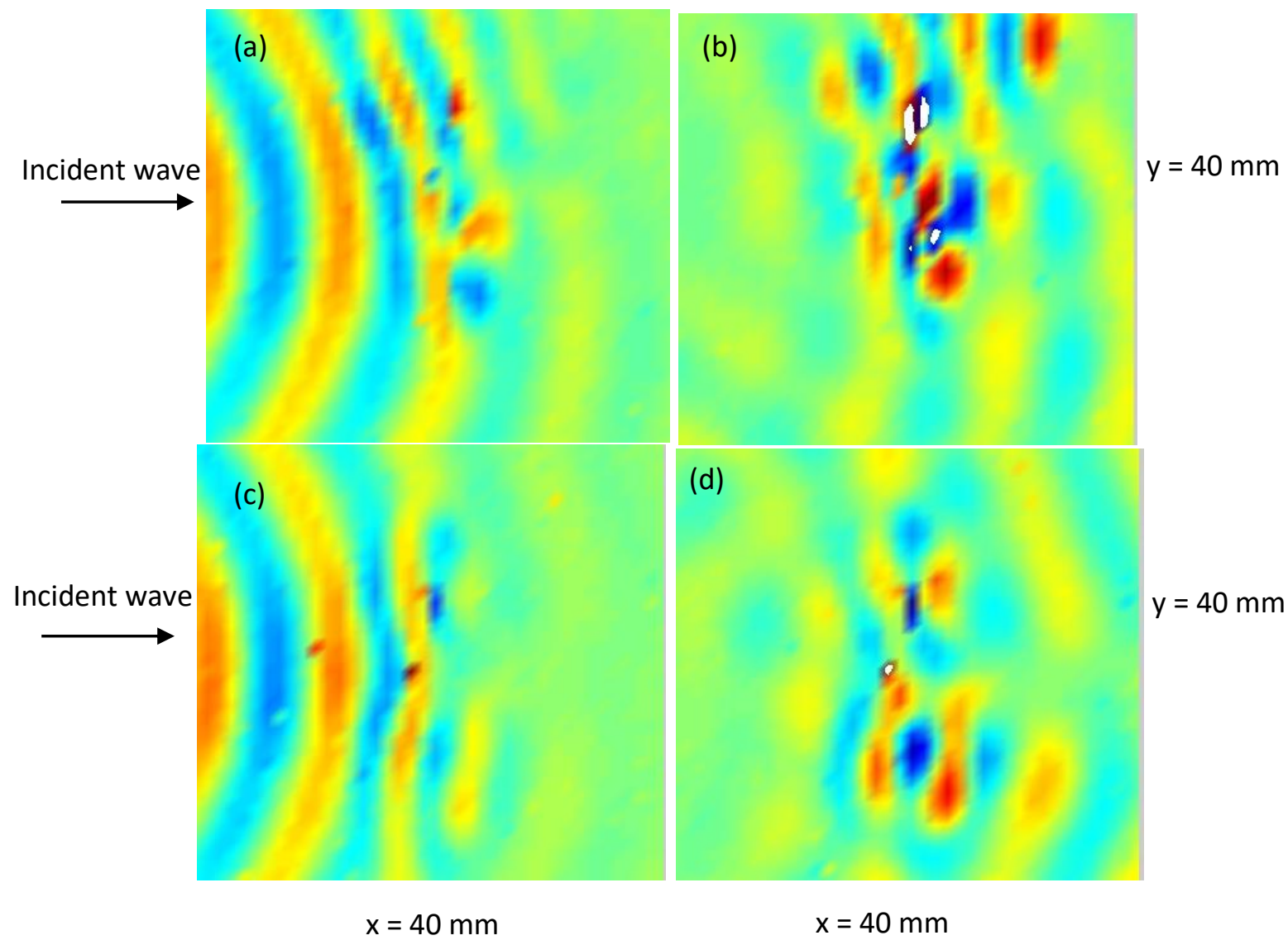

Figure 5. Experimental guided wave displacement fields in two composite plates. Plate No. 1, snapshot time: (a) $20 \mu \mathrm{s}$ and (b) $30 \mu \mathrm{s}$. Plate No. 2, snapshot time: (c) $20 \mu \mathrm{s}$ and (d) $30 \mu \mathrm{s} .7 .4 \mathrm{~J}$ impact; $40 \times 40 \mathrm{~mm}$ scanned area.

Figure 6 presents an image of the maximum amplitude of the enveloped signal over the damaged areas in both specimens. Areas of higher amplitudes can be seen that occur close to the impact location centre $(x=20 \mathrm{~mm}, y=20 \mathrm{~mm})$. This indicates the presence of severe damage, such as delamination or fibre and matrix cracking, and matches reasonably well with the visually observed size of the impact damage on the plates. Meanwhile, the undamaged area is represented by the low amplitude distribution. From the figure, three different zones can be observed and each zone has its own wave 
propagation behaviour; (i) zone 1: before the impact damage (x $<15 \mathrm{~mm}$ ), (ii) zone 2: across the impact damage $(15 \mathrm{~mm}<\mathrm{x}<25 \mathrm{~mm})$ and (iii) zone 3: behind the impact damage $(x>25 \mathrm{~mm})$. The first zone (before damage) shows the incident waves propagating towards the impact damage location.
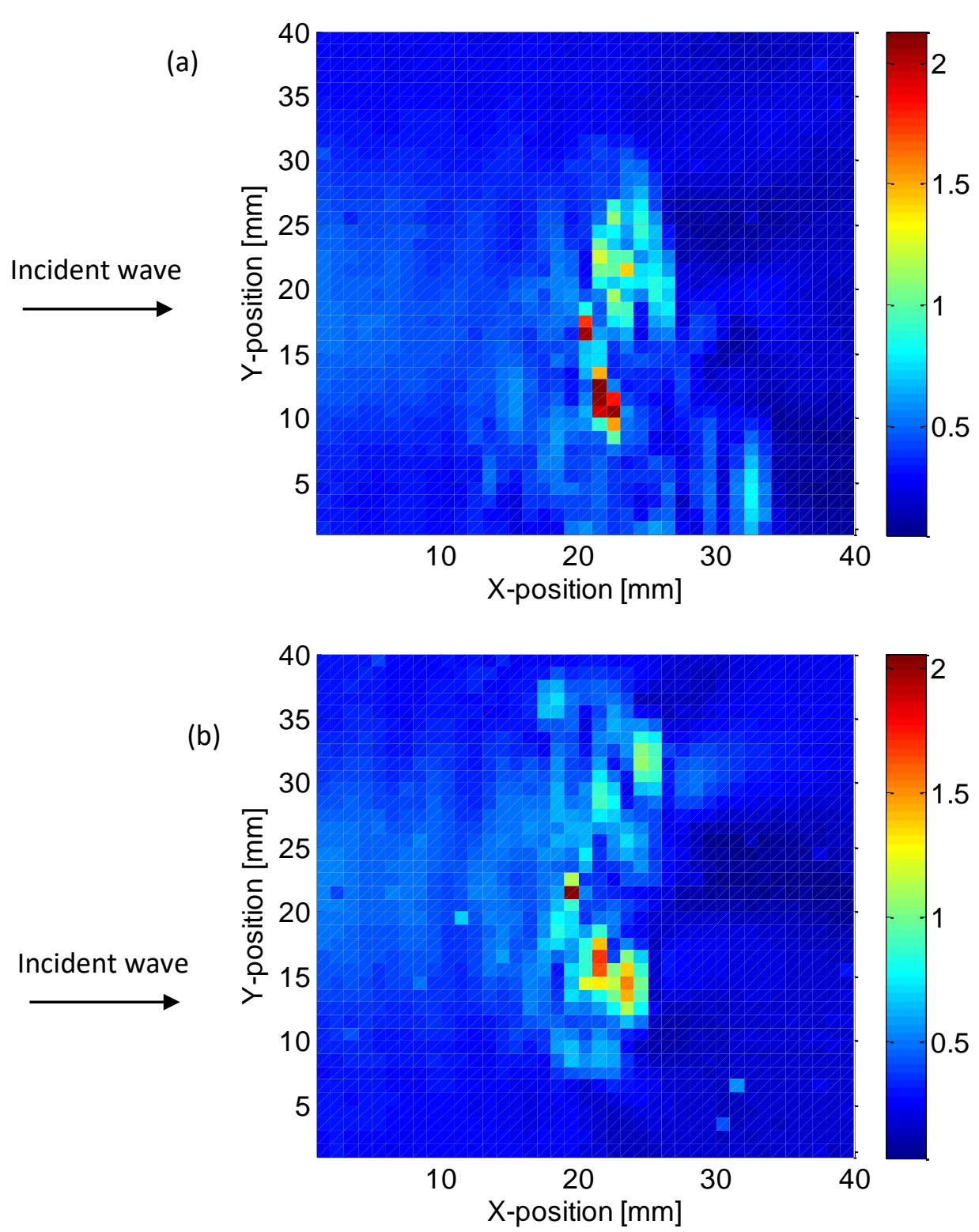

Figure 6: Experimental guided wave pulses across damaged area of composite plate: a) plate $1 ; \mathrm{b}$ ) plate 2 . Frequency $100 \mathrm{kHz} ; 40 \times 40 \mathrm{~mm}$ area with impact location at centre ( $\mathrm{x}=20 \mathrm{~mm}, \mathrm{y}=20 \mathrm{~mm})$.

Reflected waves propagating back towards the excitation source can also be seen there. Some periodical increase and decrease of the amplitude is visible in the region around $\mathrm{x}=15 \mathrm{~mm}$, potentially indicating the interference between the incident and the reflected waves at the impact damage. In zone 2 , high amplitudes of the $\mathrm{A}_{0}$ mode signals are visible, which could indicate the multiple reflections and scattering events within the impact damage area. Meanwhile, in zone 3, the transmitted waves propagating out from the damaged area are seen to be blocked in certain direction with significantly reduced 
signal amplitudes. Considerable waves transmitted across the impact damage indicate that probably little mode conversion occurred. The cross-section of the impact damage in plate no. 1 can be roughly approximated with a length of $10 \mathrm{~mm}$ (x-axis) and a width of $20 \mathrm{~mm}$ (y-axis), identified by the higher amplitude maxima. For plate no. 2, the cross section area of the impact damage can be estimated to be about $10 \times 25 \mathrm{~mm}$. Comparing to the $\mathrm{FE}$ simulation results [34], good agreement between the experimental and simulated results was achieved. Similar wave propagation behaviour before and within the impact damage can be observed from both results. The increase in amplitudes identifies the localisation of the impact damage in the measured area.

\section{CONCLUSIONS}

The use of the $\mathrm{A}_{0}$ guided ultrasonic wave mode excited at $100 \mathrm{kHz}$ for the detection and characterisation of impact damage in composite plates has been shown, with a view to employing this methodology for composite structural health monitoring. The measured wave velocities and attenuation are reasonably in agreement with the Finite Element simulated results. The highly dispersive behaviour of the $\mathrm{A}_{0}$ can be observed at frequencies below $50 \mathrm{kHz}$. Meanwhile, a repeatable scattering pattern at the impact damage was observed experimentally. The location of the impact damage can be identified by the increase in amplitude and subsequent significant amplitude reduction past the damage location. Good agreement between the experimental and finite element results was obtained. This study demonstrated that low frequency $\mathrm{A}_{0}$ guided wave mode generated by a piezoelectric transducer can be successfully employed to monitor impact damage in composite plates. The potential of guided waves for monitoring composite structures has been shown in this study, and a better understanding of the guided wave interaction with defects was achieved.

\section{ACKNOWLEDGEMENTS}

The author gratefully acknowledges the support in funding by Universiti Teknologi MARA (UiTM), Malaysia, especially from the Geran Dana Pembudayaan Penyelidikan (600-RMI/RAGS 5/3 (12/2015).

\section{REFERENCES}

[1] Richardson MOW, Wisheart MJ. Review of low-velocity impact properties of composite materials. Composites Part A: Applied Science and Manufacturing. 1996;27:1123-31.

[2] Perillo G, Vedivik NP, Echtermeyer AT. Damage development in stitch bonded GFRP composite plates under low velocity impact: Experimental and numerical results. Journal of Composite Materials. 2014;49:601-15.

[3] Shyr T-W, Pan Y-H. Impact resistance and damage characteristics of composite laminates. Composite Structures. 2003;62:193-203.

[4] Topac OT, Gozluklu B, Gurses E, Coker D. Experimental and computational study of the damage process in CFRP composite beams under low-velocity impact. Composites Part A: Applied Science and Manufacturing. 2017;92:16782. 
[5] Choi HY, Wu H-YT, Chang F-K. A New Approach toward understanding damage mechanisms and mechanics of laminated composites due to low-velocity impact: Part II-analysis. Journal of Composite Materials. 1991;25:1012-38.

[6] Lou X, Cai H, Yu P, Jiao F, Han X. Failure analysis of composite laminate under low-velocity impact based on micromechanics of failure. Composite Structures. 2017;163:238-47.

[7] Huzni S, Fonna S, Arifin A. Finite element modeling of delamination process on composite laminate using cohesive elements. International Journal of Automotive and Mechanical Engineering. 2013;7:1023-30.

[8] Wisnom MR. The role of delamination in failure of fibre-reinforced composites. Philosophical Transactions of the Royal Society A: Mathematical, Physical and Engineering Sciences. 2012;370:1850-70.

[9] Papa I, Lopresto V, Simeoli G, Langella A, Russo P. Ultrasonic damage investigation on woven jute/poly (lactic acid) composites subjected to low velocity impact. Composites Part B: Engineering.

[10] Hafizi ZM, Epaarachchi J, Lau KT. An investigation of acoustic emission signal attenuation for monitoring of progressive failure in fiberglass reinforced composite laminates. International Journal of Automotive and Mechanical Engineering. 2013;8:1442-56.

[11] Endrizzi M, Murat BIS, Fromme P, Olivo A. Edge-illumination X-ray dark-field imaging for visualising defects in composite structures. Composite Structures. 2015;134:895-9.

[12] Liang T, Ren W, Tian GY, Elradi M, Gao Y. Low energy impact damage detection in CFRP using eddy current pulsed thermography. Composite Structures. 2016;143:352-61.

[13] P. Fromme, P. D. Wilcox, M. J. S. Lowe, P. Cawley. On the development and testing of a guided ultrasonic wave array for structural integrity monitoring. IEEE Transactions on Ultrasonics, Ferroelectrics and Frequency Control. 2006;53:8.

[14] Rose J L. Ultrasonic guided waves in structural health monitoring. Key Engineering Material. 2004;273-275:7.

[15] Fromme P, Sayir MB. Measurement of the scattering of a Lamb wave by a through hole in a plate. The Journal of the Acoustical Society of America. 2002;111:116570.

[16] Ishak SI, Liu GR, Lim SP, Shang HM. Characterization of delamination in beams using fexural wve sattering aalysis. Journal of Vibration and Acoustics. 2001;123:421-7.

[17] Ju TH, Datta SK. Scattering of Impact Wave by a Crack in Composite Plate. In: Thompson DO, Chimenti DE, editors. Review of Progress in Quantitative Nondestructive Evaluation: Volume 10B. Boston, MA: Springer US; 1991. p. 1515-22.

[18] Lowe MJS, Neau G, Deschamps M. Properties of Guided Waves in Composite Plates, and Implications for NDE. AIP Conference Proceedings. 2004;700:21421.

[19] Rose JL. A Baseline and Vision of Ultrasonic Guided Wave Inspection Potential. Journal of Pressure Vessel Technology. 2002;124:273-82.

[20] Wilcox PD, Lowe MJS, Cawley P. Mode and Transducer Selection for Long Range Lamb Wave Inspection. Journal of Intelligent Material Systems and Structures. 2001;12:553-65. 
[21] Wilcox P, Lowe M, Cawley P. The effect of dispersion on long-range inspection using ultrasonic guided waves. NDT \& E International. 2001;34:1-9.

[22] Su Z, Ye L, Lu Y. Guided Lamb waves for identification of damage in composite structures: A review. Journal of Sound and Vibration. 2006;295:753-80.

[23] Lu Y, Ye L, Su Z, Yang C. Quantitative assessment of through-thickness crack size based on Lamb wave scattering in aluminium plates. NDT \& E International. 2008;41:59-68.

[24] Karunasena WM, Shah AH, Datta SK. Plane strain wave scattering by cracks in laminated composite plates. Journal of Engineering Mechanics. 1991;117:173854.

[25] Ng CT, Veidt M. Scattering analysis of fundamental anti-symmetric Lamb wave at delaminations in composite laminates. Australian Journal of Mechanical Engineering. 2011;8:197-205.

[26] Alleyne DN, Cawley P. Optimization of lamb wave inspection techniques. NDT \& E International. 1992;25:11-22.

[27] Neau G, Lowe MJS, Deschamps M. Propagation of lamb waves in anisotropic and absorbing plates: Theoretical derivation and experiments. AIP Conference Proceedings. 2002;615:1062-9.

[28] Herrmann F, Jochim B, Oßwald P, Cai L, Pitsch H, Kohse-Höinghaus K. Experimental and numerical low-temperature oxidation study of ethanol and dimethyl ether. Combustion and Flame. 2014;161:384-97.

[29] Schubert KJ, Herrmann AS. On attenuation and measurement of Lamb waves in viscoelastic composites. Composite Structures. 2011;94:177-85.

[30] Prosser WH, Seale MD, Smith BT. Time-frequency analysis of the dispersion of Lamb modes. The Journal of the Acoustical Society of America. 1999;105:266976.

[31] Biwa S, Watanabe Y, Ohno N. Analysis of wave attenuation in unidirectional viscoelastic composites by a differential scheme. Composite Science and Technology. 2003;63:237-47.

[32] Ono K, Gallego A. Attenuation of lamb waves in CFRP plates. Journal of Acoustic Emission. 2012;30:109-23.

[33] Sohn H, Dutta D, Yang JY, Park HJ, DeSimio M, Olson S, et al. Delamination detection in composites through guided wave field image processing. Composite Science and Technology. 2011;71:1250-6.

[34] Murat BIS, Khalili P, Fromme P. Scattering of guided waves at delaminations in composite plates. The Journal of the Acoustical Society of America. 2016;139:3044-52. 